\title{
Estimation of Land Surface Temperature of Yola, North Eastern Nigeria Using Landsat-7 ETM+ Satellite Image
}

\author{
A. Alkasim ${ }^{1 *}$, A. A. Hayatu ${ }^{2}$, M. K. Salihu ${ }^{3}$ \\ ${ }^{1}$ Department of Physics, Modibbo Adama University of Technology, Yola, Nigeria \\ ${ }^{2}$ Department of Physics, Adamawa State College of Education, Hong, Nigeria \\ ${ }^{3}$ Department of Pure and Applied Physics, Adamawa State University, Mubi, Nigeria \\ Email: *alkasimabbat@gmail.com
}

How to cite this paper: Alkasim, A., Hayatu, A.A. and Salihu, M.K. (2018) Estimation of Land Surface Temperature of Yola, North Eastern Nigeria Using Landsat-7 ETM+ Satellite Image. Energy and Power Engineering, 10, 449-456. https://doi.org/10.4236/epe.2018.1010028

Received: July 16, 2018

Accepted: October 27, 2018

Published: October 30, 2018

Copyright $\odot 2018$ by authors and Scientific Research Publishing Inc. This work is licensed under the Creative Commons Attribution International License (CC BY 4.0).

http://creativecommons.org/licenses/by/4.0/

\begin{abstract}
The land surface temperature of Yola (latitude $9^{\circ} 11^{\prime} \mathrm{N}$ to $9^{\circ} 20^{\prime} \mathrm{N}$ and longitude $12^{\circ} 23^{\prime} \mathrm{E}$ to $12^{\circ} 33^{\prime} \mathrm{E}$ ) North-eastern Nigeria was estimated using landsat-7 ETM+ satellite images. ENVI 4.5 software, and Thermal band 6.2 were used for the estimation, land surface temperature, from Landsat-7 ETM+ imagery sensors acquired as a digital number (DN) range from $0-255$ in thermal band. DNs were first converted to radiance values in $\mathrm{Wm}^{-2} \cdot \mathrm{sr}^{-1} \cdot \mu \mathrm{m}^{-1}$, using the bias and gain values specific to an individual pixel, then the radiance was converted eventually to surface temperature (in Kelvin). The results indicate that there is a significant variation in land surface temperature between the two different seasons in Yola. The mean surface temperatures estimated are $307.9 \mathrm{~K}$ and $298.1 \mathrm{~K}$ during the dry and rainy seasons respectively. The result obtained was compared with data obtained from Meteorological Department. The estimated land surface temperature showed a good correlation, with a difference of $2 \mathrm{~K}$ to $3 \mathrm{~K}$.
\end{abstract}

\section{Keywords}

Land Surface Temperature, Satellite Images, Thermal Band, Radiance and Landsat Data

\section{Introduction}

Land Surface Temperature (LST) can be defined as the temperature felt when the land surface is touched with bare hands or it is the skin temperature of the ground [1]. It is the temperature emitted by the surface and measured in Kelvin. It is greatly affected by the increasing greenhouse gases in the atmosphere. Land 
use/Land cover of an area can be used for estimating the amount of LST. Natural and anthropogenic activities change the Land use/Land cover of an area which in turn influences surface temperature of that area. As its value changes the local climate of the area also changes. It is an important phenomenon to be investigated. Hence, many researchers have calculated LST using various algorithms and techniques [1].

LST is maintained by the incoming solar and long wave irradiation, the outgoing terrestrial infrared radiation, the sensible and latent heat flux and the ground heat flux. Long-term and reliable estimates of LST are required for many purposes, e.g. as input to general circulation models, numerical weather prediction, climate change detection, vegetation health monitoring, change detection related to desertification processes etc. Only satellite based radiance measurements provide the temporal coverage and spatial resolution required to run these models and analyze the processes. For measurement in the atmospheric windows the top of the atmosphere radiance is dominated by surface leaving radiance. Therefore, LST can be estimated from radiances measured by satellite sensors [2].

LST is a good indicator of energy balance at the Earth's surface but its estimation is much more complicated due to the earth surface heterogeneity. Apart from the attenuation in the transmitted radiance caused by the atmosphere, the problem is also complicated by the highly variable land surface emissivity (LSE). But in the case of land surface, the emissivity dynamics has a wider range and can vary over short distances. Moreover, a proper LST validation is also difficult because the derived Surface Temperature is representative for the whole pixel, while point temperature measurement can vary over short distances. Hence, a field validation is possible only for homogeneous areas such as dense vegetation. The main problem is that it is not possible to obtain separately the LST and the emissivity from passive radiometry, because the number of unknowns is always larger than the number of measurements. For the case of a sensor with $\mathrm{N}$ spectral channels, there are $\mathrm{N}$ equations (one per channel) for solving a problem with $\mathrm{N}+1$ unknown (the $\mathrm{N}$ emissivity's plus the surface temperature). Thus the system of equations is indeterminate, and there is need of some hypothesis to solve the problem [3].

LST is one of the key parameters in the physics of Land Surface processes on a regional as well as a global scale. It combines result of all surface-atmosphere interaction and energy fluxes between the atmosphere and the ground. Therefore the ability to accurately determine thermodynamic LST is essential to many scientific problems and to the management of renewable resources [4]. With advances in thermal remote sensing techniques and in computer capabilities, measurement of LST from space allows investigations of surface climate at local, regional and global scales. The knowledge of LST is important to a range of issues and themes in earth sciences central to urban climatology, global environmental change, and human-environment interactions [5]. 
Satellite data are very useful in various fields like, astronomy, atmospheric studies, earth observation, communications, navigation, search and rescue. LST is an important parameter in atmospheric sciences as it combines the result of all surface-atmosphere interaction and energy fluxes between the ground and the atmosphere and is, therefore, a good indicator of the energy balance at the Earth's surface [6]. Surface temperature controls the surface heat and water exchange with the atmosphere which affects climatic change in the region.

Owing to the business nature and the population density of the people of Yola, the knowledge of land surface temperature is very important [7] and [8]. In this research, a land sat imaging techniques was employed to estimate the land surface temperature of some locations in Yola North-Eastern Nigeria due to in adequacy and in accuracy of some instruments available for this purpose.

\section{Methodology}

\subsection{The Study Area}

The study area Yola is a municipality that sprawls across the hillside of North-Eastern region of Nigeria. Established in 1841, it was the capital of Fulani State until it was taken over by the British in 1901 [7]. Today, it is the capital of Adamawa State, which was formed in 1991 from Gongola State. Yola is the capital city and administrative center of Adamawa State, Nigeria. The city is made up of two parts the old and new Yola. Jimeta (new Yola) is about $5 \mathrm{~km}$ North West of the old Yola. Geographically Yola is located between latitudes $9^{\circ} 11^{\prime} \mathrm{N}$ to $9^{\circ} 20^{\prime} \mathrm{N}$ and longitudes $12^{\circ} 23^{\prime} \mathrm{E}$ to $12^{\circ} 33^{\prime} \mathrm{E}$ and covers an area of about $305 \mathrm{~km}^{2}$. The area has a mean annual rainfall of $919 \mathrm{~mm}$, monthly minimum temperature of $19^{\circ} \mathrm{C}$ and maximum temperature of $37.9^{\circ} \mathrm{C}$. The mean monthly temperature is $28.5^{\circ} \mathrm{C}$. While the annual average relative humidity is $85 \%$. It is characterized by broadly flat topography with gentle undulations and hill ranges and is largely drained by the Benue River [8] [9]. The population of the study area is about 336648. The area has an internal border with republic of Cameroon due east and within the country, Gombe, Borno and Taraba States to the north, northeast and west respectively as in [8] presented in Figure 1.

\subsection{Satellite Data}

For the study Landsat satellite images of Yola were acquired for two different seasons within a year. Primarily the data was downloaded from Global Land Cover Facility home page (http://glcf.umaics.umd.edu). The spatial resolution is $30 \mathrm{~m}$ for the reflective bands. These are; band $1(0.45-0.52 \mu \mathrm{m})$, band2 $(0.52$ $0.60 \mu \mathrm{m})$, band3 $(0.63-0.69 \mu \mathrm{m})$, band4 $(0.76-0.90 \mu \mathrm{m})$, band5 $(1.55-1.75 \mu \mathrm{m})$ and band7 $(2.08-2.35 \mu \mathrm{m})$, the spatial resolution of panchromatic (band8) and thermal infrared (band6) $(10.4-12.5 \mu \mathrm{m})$ are $15 \mathrm{~m}$ and $60 \mathrm{~m}$ respectively. The approximate scene size is $200 \times 200 \mathrm{~km}$. The data is in GeoTIFF format with geographic latitude/longitude coordinates and a (approximately $30 \mathrm{~m}$ ) grid. It is referenced to the WGS84. 


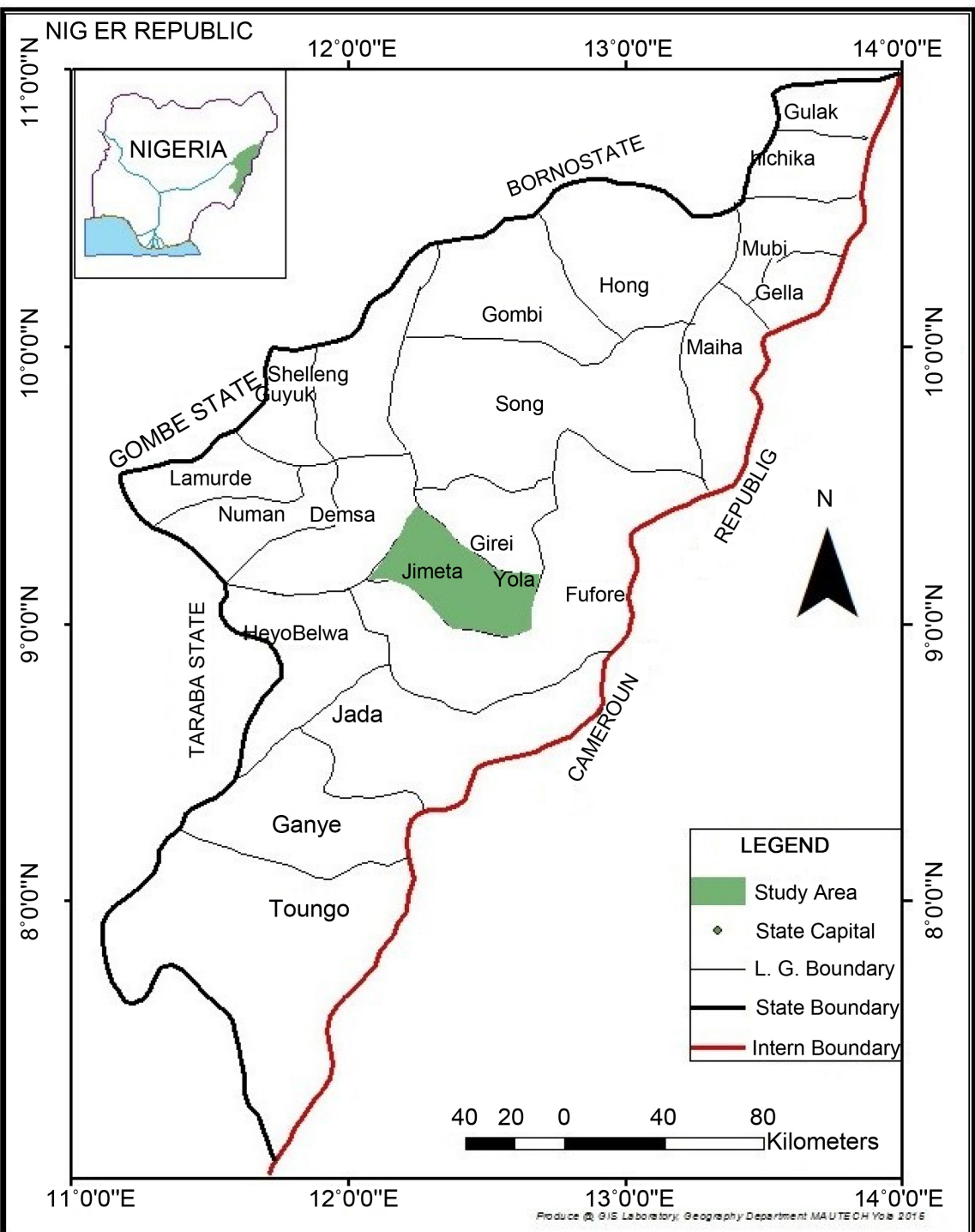

Figure 1. Map of Adamawa State indicating the study area (Source: Adebayo, 1999).

\subsection{Data Processing}

The first process is to convert the Digital numbers, DNs to radiance values using the bias and gain values specific to the individual pixel, then the radiance values were eventually converted to surface temperature in Kelvin. The effective at-sensor brightness temperature is obtained from the spectral radiance using Plank's inverse function. The surface emissivity is used to retrieve the final Surface Temperature.

\section{Step 1. Conversion of Digital Number (DN) to Spectral Radiance}

The landsat-7 ETM+ thermal data was converted to spectral radiance using an equation by [10] thus

$$
L_{\lambda}=\text { Gain } \times \mathrm{DN}+\text { Bias }
$$

where:

$L_{\lambda}$ is the spectral radiance measured over spectral bandwidth of a channel 
and DN is the digital number value recorded. The gain is computed using the relation

$$
\text { Gain }=\left(\frac{L_{\max }-L_{\min }}{255}\right)=\text { Slope of response function [5] }
$$

$L_{\text {Min }}$ (Bias) is the intercept of response function, $L_{\text {Max }}$ is the radiance measured at detector saturation in $\mathrm{W} \cdot \mathrm{m}^{-2} \cdot \mathrm{sr}^{-1} \cdot \mu \mathrm{m}$ and $L_{\mathrm{Min}}$ is the minimum radiance measured by detector in $\mathrm{W} \cdot \mathrm{m}^{-2} \cdot \mathrm{sr}^{-1} \cdot \mu \mathrm{m}$. Table 1 depicts their values for both low and high sensors for two different band numbers [11].

\section{Step 2. Conversion of Radiance to Surface Temperature}

The solar radiances $\left(L_{\lambda}\right)$ will be converted into effective satellite temperatures $T(a)[12]$.

$$
T(a)=\frac{K_{2}}{\ln \left(\frac{K_{1}}{L_{\lambda}}+1\right)}
$$

where $T(a)=$ Effective at-satellite temperature in Kelvin, $K_{1}=$ First calibration constant in $\mathrm{W} \cdot \mathrm{m}^{-2} \cdot \mathrm{sr}^{-1} \cdot \mu \mathrm{m}^{-1}, K_{2}=$ Second calibration constant in Kelvin, $L_{\lambda}=$ Spectral radiance $\mathrm{W} \cdot \mathrm{m}^{-2} \cdot \mathrm{sr}^{-1} \cdot \mu \mathrm{m}^{-1}$.

For Landsat ETM+ the NASA handbook gives $K_{1}=666.09 \mathrm{~W} \cdot \mathrm{m}^{-2} \cdot \mathrm{sr}^{-1} \cdot \mu \mathrm{m}^{-1}$ and $K_{2}=1282.71 \mathrm{~K}$ respectively. For Landsat ETM+ the values were also given in the header information of the thermal bands. Then, corrections for emissivity $(\varepsilon)$ were applied to the radiant temperatures according to the nature of land cover [13]. The emissivity corrected surface temperature can be computed as follows:

$$
T_{S}=\frac{T(a)}{\left(1+\frac{T(a)}{b}\right) \ln \varepsilon}
$$

where 1 = wavelength of emitted radiance for which the peak response and the average of the limiting wavelengths $(=11.5 \mathrm{~mm})$ [13] [14] were used,

$$
b=\frac{h c}{k_{B}}=1.438 \times 10^{-2} \mathrm{~m} \cdot \mathrm{K}
$$

where $k_{B}$ is Stefan Boltzmann's constant $=1.38 \times 10^{-23} \mathrm{~J} \cdot \mathrm{K}^{-1}, h$ is Planck's constant $=6.626 \times 10^{-34} \mathrm{~J} \cdot \mathrm{s}$, and $c$ is the velocity of light $=2.998 \times 10^{8} \mathrm{~m} \cdot \mathrm{s}^{-1}$.

\section{Results and Discussion}

The results estimated from landsat-7 ETM+ satellite images of two different seasons are presented in Table 2, Figure 2 and Figure 3 for dry and rainy

Table 1. The $L_{\mathrm{Max}}$ and $L_{\mathrm{Min}}$ values of Landsat data.

\begin{tabular}{cccc}
\hline Band No & Satellite/Sensor & $L_{\text {Max }}\left(\mathrm{W} \cdot \mathrm{m}^{-2} \cdot \mathrm{sr}^{-1} \cdot \mu \mathrm{m}\right)$ & $L_{\mathrm{Min}}\left(\mathrm{W} \cdot \mathrm{m}^{-2} \cdot \mathrm{sr}^{-1} \cdot \mu \mathrm{m}\right)$ \\
\hline 6.1 & Landsat7/ETM+ Low & 17.04 & 00.00 \\
6.2 & Landsat7/ETM+ High & 12.65 & 03.20 \\
\hline
\end{tabular}

Source: NASA Landsat-7 Hand book, 2001. 
Table 2. Land surface temperature for the two different seasons within a year.

\begin{tabular}{cccc}
\hline Seasons & $T_{\text {maximum }}(\mathrm{K})$ & $T_{\text {minimum }}(\mathrm{K})$ & $T_{\text {mean }}(\mathrm{K})$ \\
\hline Dry & 320.1 & 295.6 & 307.9 \\
Rainy & 309.3 & 286.9 & 298.1 \\
\hline
\end{tabular}

$11^{\circ} 15^{\prime} \mathrm{E}$

$11^{\circ} 20^{\prime} \mathrm{E}$
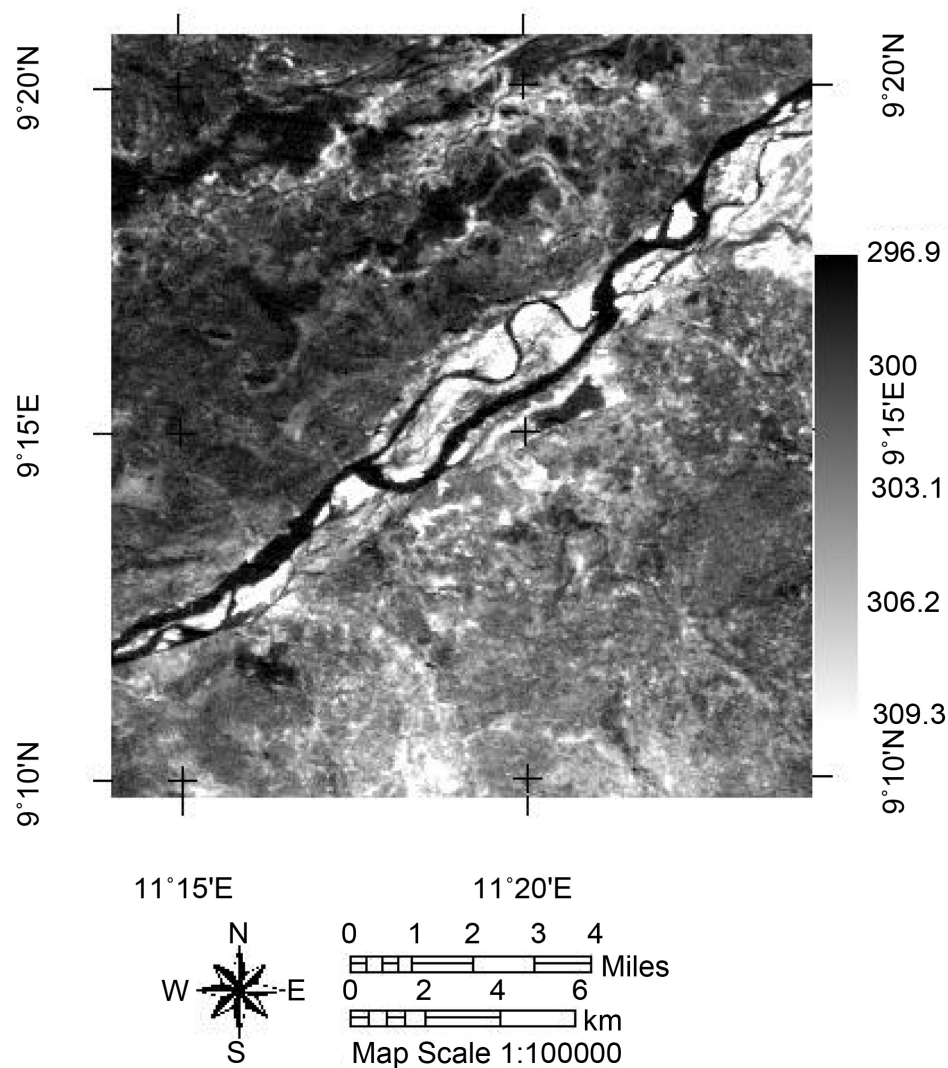

Figure 2. Dry season land surface temperature.

seasons respectively. The mean land surface temperature estimated is $307.9 \mathrm{~K}$ for dry season and $298.1 \mathrm{~K}$ for rainy season.

The thermal energy responses for the two different seasons in the study area indicate the variation in land surface temperature from a thermal band of landsat-7 ETM+ as shown in Table and figures. The difference is as a result of the presence of moist atmosphere reflecting most of the radiation, low relative humidity as well as increase in the wind speed during the rainy season than the dry season. The analysis of imagery indicates that dry season is the season with highest land surface temperature, while rainy season with lowest temperature.

The mean surface temperature $(\mathrm{K})$ for the two sets of data (i.e. Landsat-7 $\mathrm{ETM}+$ satellite image data and the corresponding temperatures measured from meteorological stations in the study area) were compared for validation. Table 3 presents the results for two selected years during the rainy and dry seasons respectively. 


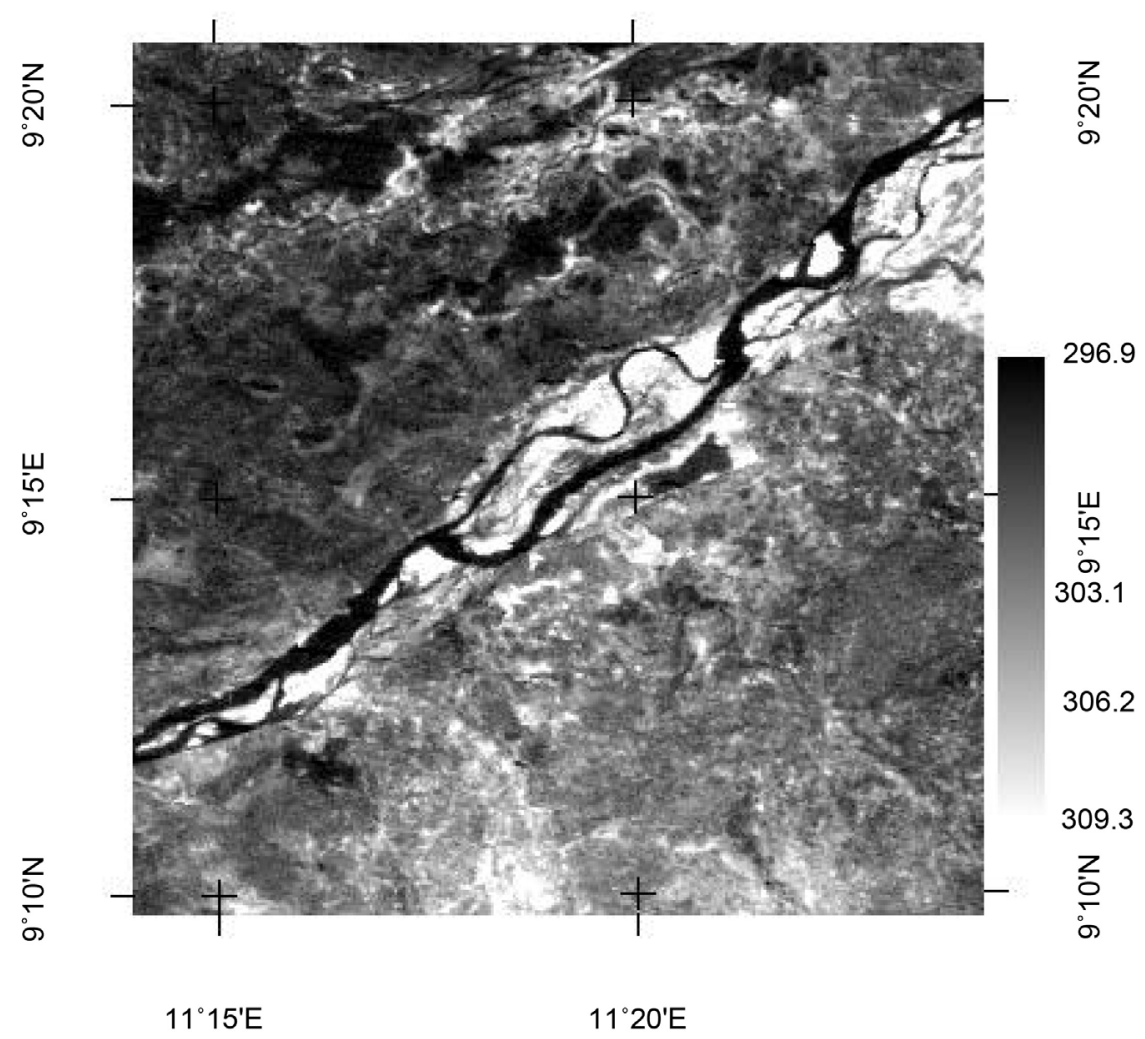

Figure 3. Rainy season land surface temperature.

Table 3. Mean values of land surface temperature of meteorological data and estimated satellite data for the selected years of study.

\begin{tabular}{ccccc}
\hline Year & $\begin{array}{c}\text { Dry season mean } \\
\text { satellite } \\
\text { Temperature }(\mathrm{K})\end{array}$ & $\begin{array}{c}\text { Dry season mean } \\
\text { meteorological } \\
\text { Temperature (K) }\end{array}$ & $\begin{array}{c}\text { Rainy season } \\
\text { mean satellite } \\
\text { Temperature (K) }\end{array}$ & $\begin{array}{c}\text { Rainy season } \\
\text { mean } \\
\text { meteorological } \\
\text { Temperature (K) }\end{array}$ \\
\hline 2015 & 303.2 & 303.9 & 301.8 & 301.9 \\
2017 & 307.9 & 304.8 & 298.1 & 301.7 \\
\hline
\end{tabular}

\section{Conclusion}

The landsat-7 ETM+ thermal band data are the freely available data, for processing land surface temperature for any topographic and climatic conditions of an area. There was an indication of the land surface temperature variations for the two different seasons as indicated in Table 2. The results are compared with meteorological data from a station in the study area (Table 3). The estimated land surface temperature showed a good correlation with little variation ranging between $2 \mathrm{~K}$ to $3 \mathrm{~K}$.

\section{Conflicts of Interest}

The authors declare no conflicts of interest regarding the publication of this paper. 


\section{References}

[1] Rajeshwari, A. and Mani, N.N. (2014) Estimation of Land Surface Temperature of Dindigul District Using Lansat 8 Data, International Journal of Research in Engineering and Technology, 3, 122-126. https://doi.org/10.15623/ijret.2014.0305025

[2] Prasanjit, D. (2005) Land Surface Temperature and Emissivity Retrieval from Satellite Measurement. A PhD Dissertation Submitted to Institute of Meteorology and Climate Research-IMK Forshunszentrum Karlsruhe, University of Karlsruhe.

[3] Tran, T.V., Le, V.T. and Hoang, T.L. (2009) Application of Thermal Remote Sensing in Study on Surface Temperature Distribution of Ho Chi Minh City. 7 th FIG Regional Conference: Spatial Data Serving People: Land Governance and the Environment: Building the Capacity, Hanoi, 19-22 October 2009, 1-11.

[4] Zhenming, W. and Jeff, D. (1989) Land Surface Temperature from Space: Physical Principles and Inverse Modelling. IEEE Transaction on Geoscience and Remote Sensing, 27, 268-278. https://doi.org/10.1109/36.17668

[5] Javed, M., Yogesh, K. and Bharath, B.D. (2008) Estimation of Land Surface Temperature of Delhi Using Landsat-7 ETM +. Journal of Industrial Geophysics Union, 12, 131-140.

[6] Prasad, A.D., Jain, K. and Gairola, A. (2013) Surface Temperature Estimation Using Landsat Data for Part of the Godavari and Tapi Basins, India. International Journal of Engineering and Advance Technology, 2, 320-322.

[7] Kemper, S. (2012) Labyrinth of Kingdoms 10,000 Miles through Islamic Africa. Norton, New York.

[8] Adebayo, A.A. (1999) Climate I: Sunshine, Temperature, Evaporation and Relative Humidity. In: Adebayo, A.A. and Tukur, A.L., eds., Adamawa State in Maps, Paracletes Publishers, Yola, 6.

[9] Ishaku, J.M. (2011) Assessment of Ground Water Quality Index for Jimeta-Yola area, North-Eastern Nigeria. Journal of Geology and Mining Research, 3, 219-231.

[10] Arvidson, T. (2002) Personal Correspondence, Landsat 7 Senior Systems Engineer. Landsat Project Science Office, Goddard Space Flight Center, Washington DC.

[11] NASA (2001) Landsat-7 Hand Book.

[12] Wukelic, G.E., Gibbons, D.E., Martucci, L.M. and Foote, H.P. (1989) Radiometric Calibration of Landsat Thematic Mapper Thermal Band. Remote Sensing of Environment, 28, 339-347. https://doi.org/10.1016/0034-4257(89)90125-9

[13] Qin, Z., Karniel, A. and Berliner, P. (2001) A Mono-Window Algorithm for Retrieving Land Surface Temperature from Landsat TM Data and Its Application to the Israel-Egypt Border Region. International Journal, 22, 3719-3746.

[14] Markham, B.L. and Barker, J.K. (1985) Spectral Characteristics of the LANDSAT Thematic Mapper Plus. International Journal of Remote Sensing, 6, 697-716. https://doi.org/10.1080/01431168508948492 